Article

\title{
Proteomic Analysis of Blood Exosomes from Healthy Females and Breast Cancer Patients Reveals an Association between Different Exosomal Bioactivity on Non-tumorigenic Epithelial Cell and Breast Cancer Cell Migration in Vitro
}

\author{
Oleg Tutanov ${ }^{1}$, Evgeniya Orlova ${ }^{2}$, Ksenia Proskura ${ }^{1,3}$, Alina Grigor'eva ${ }^{1}$, Natalia Yunusova ${ }^{4,5}$, \\ Yuri Tsentalovich ${ }^{6}$ (D) Antonina Alexandrova ${ }^{2}$ and Svetlana Tamkovich $1,7, *$ (D) \\ 1 Laboratory of Molecular Medicine, Institute of Chemical Biology and Fundamental Medicine, Siberian \\ Branch of Russian Academy of Sciences, 630090 Novosibirsk, Russia; ostutanov@gmail.com (O.T.); \\ ksen-84@list.ru (K.P.); feabelit@mail.ru (A.G.) \\ 2 Laboratory of Carcinogenesis Mechanisms, "N.N. Blokhin Cancer Research Center" of the Ministry of \\ Health of the Russian Federation, 115478 Moscow, Russia; evg19111976@yandex.ru (E.O.); \\ tonya_alex@yahoo.com (A.A.) \\ 3 Department of Mammology, Novosibirsk Regional Clinical Oncological \\ Dispensary, 630108 Novosibirsk, Russia \\ 4 Laboratory of Tumor Biochemistry, Cancer Research Institute, Tomsk National Research Medical Center, \\ Russian Academy of Science, 634028 Tomsk, Russia; bochkarevanv@oncology.tomsk.ru \\ 5 Department of Biochemistry and Molecular Biology, Siberian State Medical University, 634050 Tomsk, Russia \\ 6 Laboratory of Proteomics and Metabolomics, International Tomography Center SB RAS, \\ 630090 Novosibirsk, Russia; yura@tomo.nsc.ru \\ 7 Department of Molecular Biology and Biotechnology, Novosibirsk State University, \\ 630090 Novosibirsk, Russia \\ * Correspondence: s.tamk@niboch.nsc.ru
}

Received: 26 February 2020; Accepted: 24 March 2020; Published: 25 March 2020 updates

\begin{abstract}
Exosomes are important intercellular communication vehicles, secreted into body fluids by multiple cell types, including tumor cells. They contribute to the metastatic progression of tumor cells through paracrine signalling. It has been recently discovered that blood circulating exosomes contain distinguishable fractions of free and cell-surface-associated vesicles. We evaluated the influence of protein cargoes from exosomes from plasma, and exosomes from the total blood of healthy females (HFs) and breast cancer patients (BCPs), on cell motility. We conducted a mass spectrometric analysis of exosomal contents isolated from samples using ultrafiltration and ultracentrifugation approaches and verified their nature using transmission electron microscopy, nanoparticle tracking analysis and flow cytometry. We observed that malignant neoplasm-associated proteins in exosomes from BCP total blood were detected more often than in plasma (66\% vs. 59\%). FunRich analysis to assess Gene Ontology (GO) enrichment revealed that proteins with catalytic activities, transporter functions and protein metabolism activities were increased in exosomes from BCP blood. Finally, GO analysis revealed that proteomic profiles of exosomes from HF total blood were enriched with proteins inhibiting cell migration and invasion, which explains the low stimulating activity of exosomes from HF total blood on SKBR-3 cancer cell migration velocity. This allows exosomes to act as intermediaries providing intercellular communications through horizontal transfer of RNA and functionally active proteins, potentially affecting the development of both primary neoplasms and distant metastases.
\end{abstract}

Keywords: exosomes; migration; mass-spectrometry; breast cancer 


\section{Introduction}

Exosomes are small (30-100 nm) membrane vesicles released into the extracellular environment after the fusion of multivesicular bodies with the plasma membrane [1]. Exosome release occurs under normal physiological conditions and abnormal conditions such as cancer and other diseases. Secreted cancer cell exosomes are carried through the blood and lymph circulation and may be detected far away from parental cells [2]. These vesicular structures are highly stable and are small enough to penetrate into and interact with different tissues. Exosomes are involved in key physiological processes such as cell-to-cell communications [3], proliferation [4], migration [5], invasion [6], angiogenesis [7], and tumor growth [8] through the horizontal transfer of RNA and proteins.

Exosomal surface-exposed receptors and ligands are responsible for their bio-distribution and binding to target cells or extracellular matrices $[9,10]$. When exosomes circulate in the blood, they are in contact with blood cells, and after such interactions with cell plasma membranes, some do not undergo immediate membrane fusion/internalization but remain at the cell surface as cell-associated vesicles for some time. Indeed, it has been recently discovered that blood circulating exosomes contain distinguishable fractions of free and cell-surface-associated vesicles [11,12]. The role of blood cell-surface-associated exosomes has not been fully elucidated. Recently, we demonstrated that miRNA and proteins from blood cell-bound exosomes represented valuable sources of materials for cancer diagnostics $[11,12]$.

In the present work, we explored the biological activity of cell-free and blood cell-surface-associated exosomes, materials that were derived from a previous study [12]. We showed that protein cargoes in exosomes from plasma and total blood of healthy females (HFs) and breast cancer patients (BCPs) correlated with redistribution between cell-free and cell-associated fractions of exosomes, and with alterations in the motility characteristics of certain cells.

\section{Material and Methods}

\subsection{Ethics Statement}

Blood samples from previously untreated luminal BCPs $(n=23$, age 31-79 years, median age 58) were obtained from Novosibirsk Regional Oncology Dispensary (Table 1).

Table 1. General Clinical Characteristics of Breast Cancer Patients.

\begin{tabular}{ccc}
\hline & & No (\%) \\
\hline \multirow{4}{*}{ Tumor Stage } & $\mathrm{T} 1$ & $11(48)$ \\
& $\mathrm{T} 2$ & $9(39)$ \\
& $\mathrm{T} 3$ & $1(4)$ \\
& $\mathrm{T} 4$ & $2(9)$ \\
\hline \multirow{4}{*}{ Nodal Status } & $\mathrm{N} 0$ & $14(61)$ \\
& $\mathrm{N} 1$ & $7(30)$ \\
& $\mathrm{N} 2$ & $1(4)$ \\
& $\mathrm{N} 3$ & $1(4)$ \\
Receptor Status & $\mathrm{M} 0$ & $23(100)$ \\
& ER and/or Pr + & $15(65)$ \\
& ER and Pr - & $5(22)$ \\
HER2 Status & Unknown & $3(13)$ \\
& Positive & $15(65)$ \\
& Negative & $5(22)$ \\
& Unknown & $3(13)$ \\
Ki-67 & $<10$ & $4(17)$ \\
& $10 \leq \leq 20$ & $6(26)$ \\
& $>20$ & $10(43)$ \\
Histologic & Unknown & $3(13)$ \\
Grade & II & $16(70)$ \\
Infiltrative Ductal Carcinoma & $23(100 \%)$ \\
\hline \multicolumn{2}{c}{ Total Patients } & $23(100 \%)$ \\
\hline
\end{tabular}


Blood samples from HFs ( $\mathrm{n}=21$, age 38-65 years, median age 56), collected for blood transfusion, were obtained from Novosibirsk Central Clinical Hospital. HFs did not have any female-related disorders (mastopathy, endometriosis, etc.) or malignant diseases. Written informed consent was obtained from every participant and the Ethical Committees of the Dispensary, Hospital and Institute approved the studies. Human samples were obtained according to the principles expressed in the Declaration of Helsinki.

\subsection{Exosome Isolation}

Venous blood $(9 \mathrm{~mL})$ was collected in $\mathrm{K}_{3}$ EDTA spray-coated vacutainers (Improvacuter, Guangzhou, China, cat. no. 694091210), immediately mixed using a rotary mixer, placed at + $4{ }^{\circ} \mathrm{C}$ and processed within an hour after blood taking.

The blood sample was divided into two equal parts. One part was used for the isolation of plasma exosomes, and the second for the isolation of total blood exosomes. To isolate the plasma exosomes, blood cells were pelleted by centrifugation at $290 \mathrm{~g}$ for $20 \mathrm{~min}$, blood plasma was transferred to a new tube and centrifuged a second time at $1200 \mathrm{~g}$ for $20 \mathrm{~min}$. To remove cell debris, plasma samples were centrifuged at $17,000 \mathrm{~g}$ at $4{ }^{\circ} \mathrm{C}$ for $20 \mathrm{~min}$.

Plasma supernatants were diluted in PBS (P4417, Sigma, Saint Louis, Missouri, USA) with $5 \mathrm{mM}$ EDTA in a 1:5 ratio, passed through a $100 \mathrm{~nm}$ pore-size filter (Minisart high flow, 16553-K, Sartorius, Göttingen, Germany), and the filtrates centrifuged for $90 \mathrm{~min}$ at $100,000 \mathrm{~g}\left(4^{\circ} \mathrm{C}\right)$. Pellets were suspended in $12 \mathrm{~mL}$ PBS and again centrifuged for $90 \mathrm{~min}$ at $100,000 \mathrm{~g}\left(4^{\circ} \mathrm{C}\right)$. This washing stage was performed three times. Then supernatants were removed and pellets resuspended in $150 \mu \mathrm{L}$ PBS.

To isolate total blood exosomes, a previous protocol was used [12]. Briefly, equal volumes of elution buffer (BioSilica Ltd, Novosibirsk, Russia) were added to blood samples, and incubated on a rotary mixer $(10 \mathrm{rpm})$ for $4 \mathrm{~min}$, at room temperature. Total blood exosomes were isolated using the same procedures as for plasma exosome isolation.

To study the impact of exosomes on cell migration, half the exosome samples from different individuals were mixed, to generate two samples (plasma exosomes and total blood exosomes) from HFs and two samples (plasma exosomes and total blood exosomes) from BCPs. Individual and mixed samples were frozen in liquid nitrogen and stored in aliquots at $-80^{\circ} \mathrm{C}$ until required.

\subsection{Electron Microscopy of Exosomes}

For negative staining, a drop of exosomes was incubated for $1 \mathrm{~min}$ on a copper grid covered with formvar film, stabilized by carbon. Then, grids were exposed for $5-10 \mathrm{~s}$ on a drop of $0.5 \%$ uranyl acetate or $2 \%$ phosphotungstic acid. The grids holding the adsorbed exosomes, or ultrathin sections, were examined on a transmission electron microscope (TEM) (JEM 1400 (Jeol, Tokyo, Japan) with a digital camera Veleta (EMSIS, Münster, Germany)). Exosome measurements were made directly on the camera screen using iTEM (EMSIS, Münster, Germany) software.

\subsection{Nanoparticle Tracking Analysis}

Exosome quantities were analyzed using a nanoparticle tracking analysis (NTA) system, NanoSight NS300 (Malvern, Surrey, UK). Depending on the concentration of the particles, the samples were diluted 50-100 fold in $0.1 \mu \mathrm{m}$ filtered PBS to obtain optimal conditions for NTA concentration measurements. Each sample was measured in triplicate, with a camera setting of 15, an acquisition time of $30 \mathrm{~s}$ and a detection threshold setting of 5 . At least 200 completed tracks were analyzed per video. NTA analytical software version 2.3 was used for data analysis and capture.

\subsection{Protein Quantification}

To estimate protein concentrations, $7.5 \mu \mathrm{L}$ of an exosome suspension was mixed with lysis buffer (0.25 M Tris-HCl, 8\% SDS, $0.2 \mathrm{MDTT}, \mathrm{pH} 6.8)$, incubated on ice (10 min), boiled ( $95^{\circ} \mathrm{C}$ for $10 \mathrm{~min}$ ) and cooled. After centrifugation $(12,000 \mathrm{~g}, 10 \mathrm{~min})$, the protein concentration was measured using a 
fluorometric protein assay (NanoOrange®Protein Quantitation Kit, Molecular Probes, Waltham, USA) according to the manufacturer's instructions.

\subsection{Flow Cytometry Analysis}

For exosome immunoprecipitation and their subsequent analysis by fluorescence-activated cell sorting (FACS), $4 \mu \mathrm{m}$ diameter aldehyde/sulfate latex beads (Interfacial Dynamics, Portland, Oregon, USA) were incubated with purified anti-CD9 or anti-CD24 (BD Biosciences, San Jose, CA, USA) or anti-ADAM-10 (Abcam, Cambridge, UK) antibodies at $22{ }^{\circ} \mathrm{C}$ overnight, with gentle agitation as previously described [13]. For FACS analysis, $30 \mu \mathrm{g}$ exosomes were incubated with $3 \times 10^{5}$ anti-CD9, anti-CD24 or anti-ADAM-10 beads in $150 \mu \mathrm{L}$ of PBS at $4{ }^{\circ} \mathrm{C}$ overnight, with gentle agitation. The reaction was stopped by incubation with $0.2 \mathrm{M}$ glycine for $30 \mathrm{~min}$. The exosome-bead complexes were washed twice in FACS buffer ( $3 \%$ exosome depleted fetal bovine serum (FBS, Gibco, Gaithersburg, Maryland, USA) in PBS). The bead-bound exosomes were then incubated with human IgG (BD Biosciences, San Jose, CA, USA) at $4^{\circ} \mathrm{C}$ for $30 \mathrm{~min}$, with subsequent washing in FACS buffer, and incubation with fluorescein-conjugated anti-CD9, anti-CD24, anti-CD63, anti-CD81 or isotype antibodies (BD Biosciences, San Jose, CA, USA) for $40 \mathrm{~min}$ at room temperature, with gentle agitation. All complexes were washed twice, suspended in $300 \mu \mathrm{L}$ of FACS buffer and analyzed by flow cytometry on the FACS Canto II (BD Biosciences, San Jose, CA, USA), using FACS Diva 6.1 Software. The median fluorescence intensity (MFI) of stained exosomes was captured and analyzed and compared to the isotype control.

\subsection{Cell Lines}

MCF10A non-tumorigenic epithelial cells (ATCC®CRL-10317 ${ }^{\mathrm{TM}}$ ), were cultured in Dulbecco's Modified Eagle Medium/Nutrient Mixture F-12 (DMEM/F12) supplemented with 5\% horse serum, GlutaMAX-I $(10 \mu \mathrm{L} / \mathrm{mL})$, epidermal growth factor (EGF) $(20 \mathrm{ng} / \mathrm{mL})$, hydrocortisone $(0.5 \mu \mathrm{g} / \mathrm{mL})$, cholera toxin $(100 \mathrm{ng} / \mathrm{mL})$, insulin $(10 \mu \mathrm{g} / \mathrm{mL}), \mathrm{NaHCO}_{3}(32.5 \mu \mathrm{g} / \mathrm{mL})$, penicillin $(100 \mathrm{U} / \mathrm{mL})$, and streptomycin $(100 \mu \mathrm{g} / \mathrm{mL})$. SKBR-3 human breast cancer cells (ATCC $\left(H T B-30^{\mathrm{TM}}\right)$, were cultured in Dulbecco's Modified Eagle's Medium (DMEM) supplemented with 10\% FBS, penicillin (100 U/mL) and streptomycin $(100 \mu \mathrm{g} / \mathrm{mL})$. Some assays were performed in the absence of serum media, and the presence or absence of epidermal growth factor.

\subsection{Cell Migration Assay}

For 2D migration assays, cells were plated onto an 8-well slide (NuncTM Lab-TekTM, ThermoScientific, Loughborough, UK), at a density of $12 \times 10^{3}$ and $13.5 \times 10^{3}$ cells/well, for MCF10A and SK-BR-3, respectively. For MCF10A cells, the slides were coated with $1 \mathrm{mg} / \mathrm{mL}$ bovine fibronectin (Sigma-Aldrich, Darmstadt, Germany) before experiments. All 8-well slides were then incubated at $37^{\circ} \mathrm{C}$ in a humidified atmosphere at $5 \% \mathrm{CO}_{2}$ for $24 \mathrm{~h}$ (SKBR-3) or $48 \mathrm{~h}$ (MCF10A). The culture medium was then replaced by DMEM (SKBR-3) or DMEM/F12 (MCF10A), without serum and EGF for $5 \mathrm{~h}$. After this period, the medium was changed to F12 medium with $15 \mathrm{mM}$ HEPES, with or without serum/EGF/exosomes. We added $1-2 \times 10^{8}$ exosomes per well, which was similar to exosome concentrations in plasma, and based on our and others' previous findings [11]. Slides were placed inside a $37^{\circ} \mathrm{C}$ incubation chamber of a Nikon Eclipse-Ti microscope, equipped with an ORCA-ER Hamamatsu camera controlled by NIS-Elements AR2.30 software (Nikon, Tokyo, Japan). Images were acquired with a Plan-Neofluar $\times 10$ and $\times 20$ objectives every $5 \mathrm{~min}$, for $15-20 \mathrm{~h}$. To estimate cell motility, we analyzed the number of motile cells under each condition (a migrated cell was defined if it moved a distance longer than its radius), and the velocity of moving cells, based on tracking cell migration using MTrackJpluging in ImageJ. Two-three fields of view were recorded for each condition, in three independent experiments. 


\subsection{Mass Spectrometry Analysis}

Individual exosome samples were separated based on their molecular weight using SDS disc electrophoresis. The gels were stained by Coomassie Brilliant Blue R250 (Sigma, Darmstadt, Germany). The PAAG fragments containing proteins under study were treated using the modified Rosenfeld method [14]. Briefly, PAAG fragments with proteins were washed from Coomassie R250 and SDS with an aqueous solution containing 50\% acetonitrile and $0.1 \%$ trifluoroacetic acid. Proteins absorbed in the gel were reduced with $45 \mathrm{mM}$ DTT in $0.2 \mathrm{M}$ ammonium bicarbonate at $60^{\circ} \mathrm{C}$ for $30 \mathrm{~min}$, followed by protein alkylation with $100 \mathrm{mM}$ iodoacetamide in $0.2 \mathrm{M}$ ammonium bicarbonate, at room temperature for $30 \mathrm{~min}$. The gel fragments were dehydrated in 100\% acetonitrile. A $0.2 \mathrm{mM}$ trypsin solution (modified by reductive methylation) (Sigma, T6567, Darmstadt, Germany), in a mixture with $0.1 \mathrm{M}$ ammonium bicarbonate and $5 \mu \mathrm{M} \mathrm{CaCl}_{2}$, was added to each gel fragment and incubated for $30 \mathrm{~min}$ at room temperature. Then, peptide extraction buffer $(60 \mu \mathrm{L})$ was added to the gel fragments, and samples were incubated for $16-18 \mathrm{~h}$ at $37^{\circ} \mathrm{C}$. The peptide fragments of proteins extracted from the gel were concentrated and desalted using C18 ZipTips micro-columns (Millipore, Darmstadt, Germany) according to the manufacturer's instructions. The peptide mixture was eluted from the micro-column, on a target of the device plate with the saturated matrix solution.

Mass-spectra were registered at the Center of Collective Use «Mass spectrometric investigations» SB RAS on an Ultraflex III MALDI-TOF/TOF mass spectrometer (BrukerDaltonics, Bremen, Germany) in positive mode, with the range 700-3000 Da, and with 2,5-dihydroxybenzoic acid as a matrix. Proteins were identified by searching for appropriate candidates in annotated NCBI and SwissProt databases using Mascot software (Matrix Science Ltd., London, UK, www.matrixscience.com/search_form_select. $\mathrm{html}$ ). The following parameters were used for searches: the acceptable mass deviation of the charged peptide (50 ppm) - 0.05Da; the acceptable number of missed cleavage sites-2; carbamidomethylation of cysteine residues was chosen as a fixed modification and the presence of oxidized methionine residues was chosen as a variable modification; identification reliability not lower than $95 \%$.

\subsection{Bioinformatics and Gene Ontology (GO) Analysis of Proteomic Profiles}

Venn diagrams, illustrating shared proteins from exosome samples from plasma and total blood, as well as GO enrichment analysis of the exosomal proteome, were performed using a FunRich version 3.1.3 software package [15]. GO profiling of exosomal proteins involved in cell migration and motility was performed using the QuickGO annotation terms (lists of obtained proteins were searched against GO terms cell motility (GO:0048870), cell migration (GO:0016477) and negative regulation of cell motility (GO:2000146)) [16]. Profiling of the differently expressed exosomal proteins during the development of various malignant diseases was performed using the dbDEPC 3.0 database [17]. The involvement of exosomal proteins in cancer invasion was routinely analyzed by searching the PubMed database on relevant publications for each protein.

\subsection{Statistical Analysis}

Statistical calculations were performed using Statistica 6.0 software and GraphPad PRISM 5 software (GraphPad Software, La Jolla, CA, USA). All data were expressed either as the median with interquartile ranges or as means with standard errors. To evaluate differences, the Mann-Whitney U-test was performed. $p$ values $<0.05$ were considered statistically significant. Cell motility data represented at least four independent experiments for the SKBR-3 cell line, and two independent experiments for the MCF10A cell line. 


\section{Results}

\subsection{Characterization of Plasma and Total Blood Vesicles as Exosomes}

The morphology of single plasma vesicles and total blood vesicles was examined by TEM to reveal spherical vesicles of $40-100 \mathrm{~nm}$ in diameter, with a bilayer membrane (Figure 1). Vesicles with damaged membranes did not exceed $10 \%$, and the portion of microvesicles (with the size smaller than $30 \mathrm{~nm}$ ), was no more than 15\%. NTA analysis revealed that vesicle sizes were within the 31-226 nm range, with a median hydrodynamic radius of 96-131 nm (Table 2). Although both NTA and TEM demonstrated similar extracellular vesicles characteristics in terms of size distribution, in general, the size values measured by TEM can be lower than those measured by NTA, as recently described [18-20].
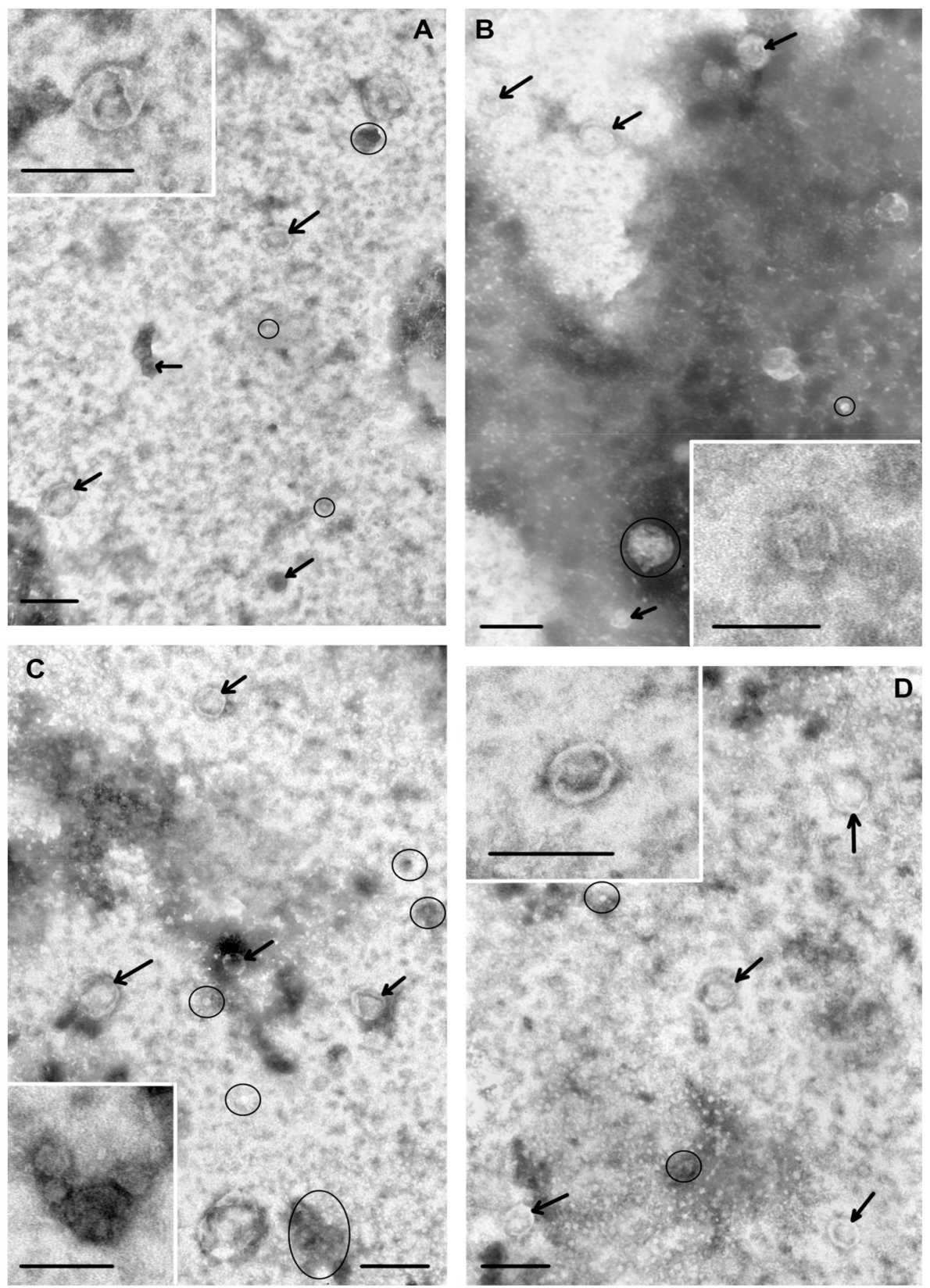

Figure 1. Total view of exosome preparation obtained from: blood plasma of HFs (A), blood plasma of BCPs (B), total blood of HFs (C), total blood of BCPs (D). Inserts show exosomes. Arrows indicate exosomes, ellipses- «non-vesicles». Scale bars correspond to $100 \mathrm{~nm}$. Electron microscopy, negative staining by phosphotungstate acid. 
Table 2. Concentration and Size-distribution of Plasma Exosomes and Total Blood Exosomes Isolated from the Blood of HFs and BCPs. Data of NTA (Malvern, NS-300).

\begin{tabular}{|c|c|c|c|}
\hline \multicolumn{2}{|c|}{ 1. Source of Exosomes } & $\begin{array}{l}\text { Median and Range of Exosomes } \\
\text { Concentration } \times 10^{7} / \mathrm{ml} \text { of blood }\end{array}$ & $\begin{array}{c}\text { Median } \pm \text { SE } \\
\text { of Exosome Size, } \mathrm{nm}\end{array}$ \\
\hline \multirow[t]{2}{*}{ HFs } & Plasma & $\begin{array}{c}8 \\
4-10\end{array}$ & $96 \pm 16$ \\
\hline & Total Blood & $\begin{array}{c}26 \\
25-27\end{array}$ & $130 \pm 5$ \\
\hline \multirow{2}{*}{$\begin{array}{l}\text { BCPs } \\
\text { Luminal } \\
\text { Subtype }\end{array}$} & Plasma & $\begin{array}{c}23 \\
5-88\end{array}$ & $127 \pm 7$ \\
\hline & Total Blood & $\begin{array}{c}24 \\
7-92\end{array}$ & $129 \pm 12$ \\
\hline \multirow{2}{*}{$\begin{array}{c}\text { BCPs } \\
\text { Triple-negative } \\
\text { Subtype }\end{array}$} & Plasma & $\begin{array}{c}19 \\
9-30\end{array}$ & $103 \pm 72$ \\
\hline & Total Blood & $\begin{array}{c}31 \\
28-63\end{array}$ & $131 \pm 95$ \\
\hline
\end{tabular}

The presence of exosomal markers was confirmed by flow cytometry. Two types of monoclonal antibodies were used to evaluate exosome maturity: antibodies to the tetraspanin family of receptors, CD9, CD63 and CD81, which are essential structural components of exosome membranes that mediate exosome adhesion to recipient cell surfaces [21], and the antibody specifically binding to the CD24 receptor, which is a marker of actively dividing and differentiating cells, including epithelium [22]. Vesicles isolated from plasma and total blood expressed CD63, CD9, CD24 and CD81 (Table 3); thus, they were classified as exosomes. Collectively, these data demonstrate that vesicles isolated from plasma and total blood demonstrate all characteristics of exosomes.

Table 3. Expression of CD 24, CD 63 and CD 81 on the Surface of Exosomes from Plasma and Total Blood of HFs and BCPs*

\begin{tabular}{cccccc}
\hline \multirow{2}{*}{ 2. Source of Exosomes } & \multicolumn{2}{c}{ CD9-Positive Exosomes } & \multicolumn{2}{c}{ CD24-Positive Exosomes } \\
\cline { 2 - 6 } & & $\begin{array}{c}\text { CD 63 } \\
\text { Expression }\end{array}$ & $\begin{array}{c}\text { CD 81 } \\
\text { Expression }\end{array}$ & $\begin{array}{c}\text { CD 9 } \\
\text { Expression }\end{array}$ & $\begin{array}{c}\text { CD 63 } \\
\text { Expression }\end{array}$ \\
\hline \multirow{2}{*}{ HFs } & Plasma & $513 \pm 76$ & $645 \pm 97$ & $1048 \pm 120$ & $523 \pm 75$ \\
\cline { 2 - 6 } & Total blood & $523 \pm 42$ & $698 \pm 63$ & $832 \pm 81$ & $540 \pm 44$ \\
\hline $\begin{array}{c}\text { BCPs } \\
\text { Luminal Subtype }\end{array}$ & Plasma & $464 \pm 48$ & $630 \pm 67$ & $1078 \pm 116$ & $470 \pm 56$ \\
\cline { 2 - 6 } & Total blood & $493 \pm 47$ & $689 \pm 70$ & $1153 \pm 110$ & $494 \pm 48$ \\
\hline \multirow{2}{*}{$\begin{array}{c}\text { BCPs } \\
\text { Triple-negative Subtype }\end{array}$} & Plasma & $515 \pm 52$ & $688 \pm 48$ & $859 \pm 85$ & $550 \pm 53$ \\
\cline { 2 - 6 } & Total blood & $543 \pm 43$ & $704 \pm 49$ & $742 \pm 67$ & $527 \pm 58$ \\
\hline
\end{tabular}

*, data represent median fluorescence intensity $(\mathrm{MFI}) \pm \mathrm{SEM}$.

\subsection{Quantitative and Sub-Population Analysis of Exosomes from Plasma and Total Blood}

NTA assessed the size and concentration of pooled exosomes in our samples. NTA was performed in triplicate for each sample, and the reproducibility of counting between runs was approximately $15 \%$. Plasma exosome sizes from HF blood and triple-negative breast cancer type patient's blood were lower than total blood exosomes, except for luminal subtype BCPs (Table 2). To characterize the proportion of cell-free and blood cell-associated exosomes, the concentrations of plasma exosomes and total blood exosomes were estimated (Table 2). The data indicated that $31 \%$ of blood exosomes circulated in HF plasma, 39\% in triple-negative subtype BCP plasma, and 96\% in luminal subtype BCP plasma. Thus, the proportion of blood cell-associated exosomes in breast cancer was decreased, in comparison with the healthy state.

Various exosome types circulate in the blood of healthy donors and patients with different cancers, and surface proteins mainly represented by CD9, CD24, CD63 and CD81 are considered 
as universal markers of blood exosomes [23]. Using combinations of unconjugated and conjugated antibodies, we characterized subpopulations of exosomes from plasma and total blood and found that subpopulation compositions of exosomes from plasma and total blood of HFs and BCPs were similar: CD24/CD9 > CD9/CD81 > CD24/CD63 ₹ CD9/CD63 (Table 3). Thus, in both cell-free and blood cell-associated samples of HFs and BCPs, exosomes expressing CD9 and CD24 receptors were most frequently detected.

\subsection{Exosomes from Plasma and Total Blood Increase Cell Migration Activities}

The effects of exosomes from plasma and total blood from HFs and BCPs, on cell migration, were tested in MCF10A and SKBR-3 cells. MCF10A is a spontaneously immortalized, non-malignant breast cell line from a patient with benign fibrocystic disease, and is the founder cell line of a more progressively aggressive family of breast cancer lines [24]. These cells, therefore, act as a useful control cell model to assess the oncogenic potential of blood exosomes from cancer patients.

Non-tumorigenic epithelial MCF10A cells on 2D surfaces are located singly or combined into cell islands of various sizes. Under serum-free and EGF-free conditions, the cells were practically immobile and established good cell-to-cell contacts. The addition of horse serum and/or EGF to these cells causes mobility stimulation (Table 4). Migrated cell numbers and their velocities increased significantly for both individual MCF10A cells and cells within islands (Figure 2A, Table 4, Figure S1A). The addition of exosomes from HF plasma and from plasma and total BCP blood led to a significant increase in the motile cell numbers in the absence of serum and EGF (Table 4); similarly, the movement of several whole-cell islands toward each other was also observed. Exosomes from HF total blood did not cause this effect: the migration was observed only for several cells at the periphery of an island. It should be noted that exosome addition does not affect the migration velocity of MCF10A cells (Figure 2A, Figure S1A).

Table 4. The Proportion of Motile Cells in Response to Exosome Treatment.

\begin{tabular}{|c|c|c|}
\hline \multirow[t]{2}{*}{ Source of Exosomes } & \multicolumn{2}{|c|}{$\begin{array}{l}\text { Percentage of Migrating Cells, } \\
\text { Median and } 25-75 \% \text { Percentile }\end{array}$} \\
\hline & MCF10A Cells & SKBR-3 Cells \\
\hline \multirow{3}{*}{ Negative Control } & 6.5 & 2.0 \\
\hline & $3.0-7.3$ & $0.5-3$ \\
\hline & - & - \\
\hline \multirow{3}{*}{ Positive Control } & 96.5 & 15.0 \\
\hline & $95.8-100$ & $14.0-16.0$ \\
\hline & $p<0.0001$ & $p=0.0024$ \\
\hline \multirow{3}{*}{ from HF Plasma } & 9.0 & 6.5 \\
\hline & $7.3-11.5$ & $3.3-9.8$ \\
\hline & $p=0.0399$ & NS \\
\hline \multirow{3}{*}{ from HF Total Blood } & 12.0 & 5.0 \\
\hline & $4.3-13.5$ & $1.5-6.5$ \\
\hline & NS & NS \\
\hline \multirow{3}{*}{ from BCP Plasma } & 17.0 & 6.0 \\
\hline & $4.3-17.8$ & $4.5-8.0$ \\
\hline & $p=0.0179$ & NS \\
\hline \multirow{3}{*}{ from BCP Total Blood } & 24.0 & 5.0 \\
\hline & $13.8-26.3$ & $1.0-6.0$ \\
\hline & $p=0.0097$ & NS \\
\hline
\end{tabular}




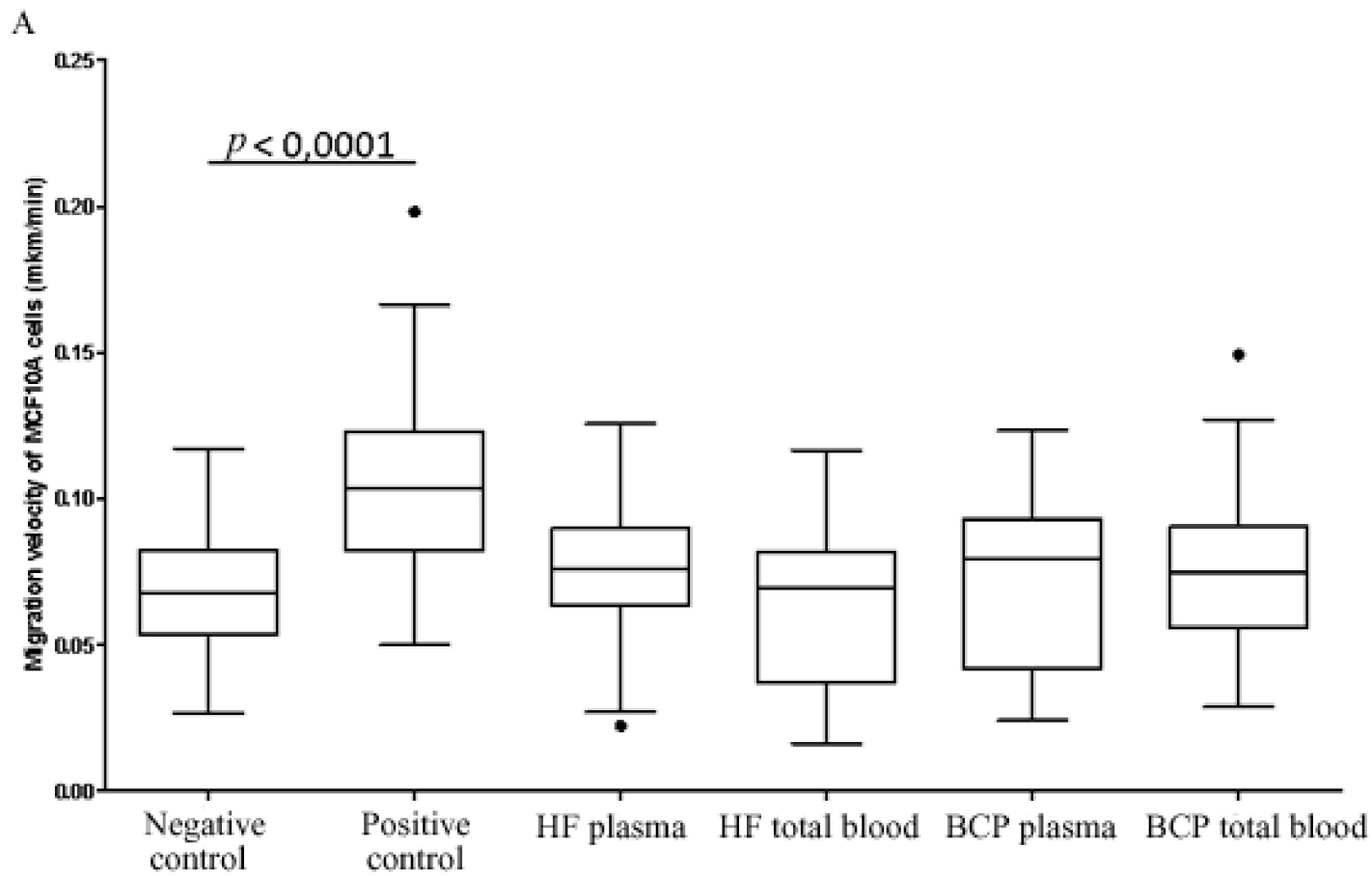

B

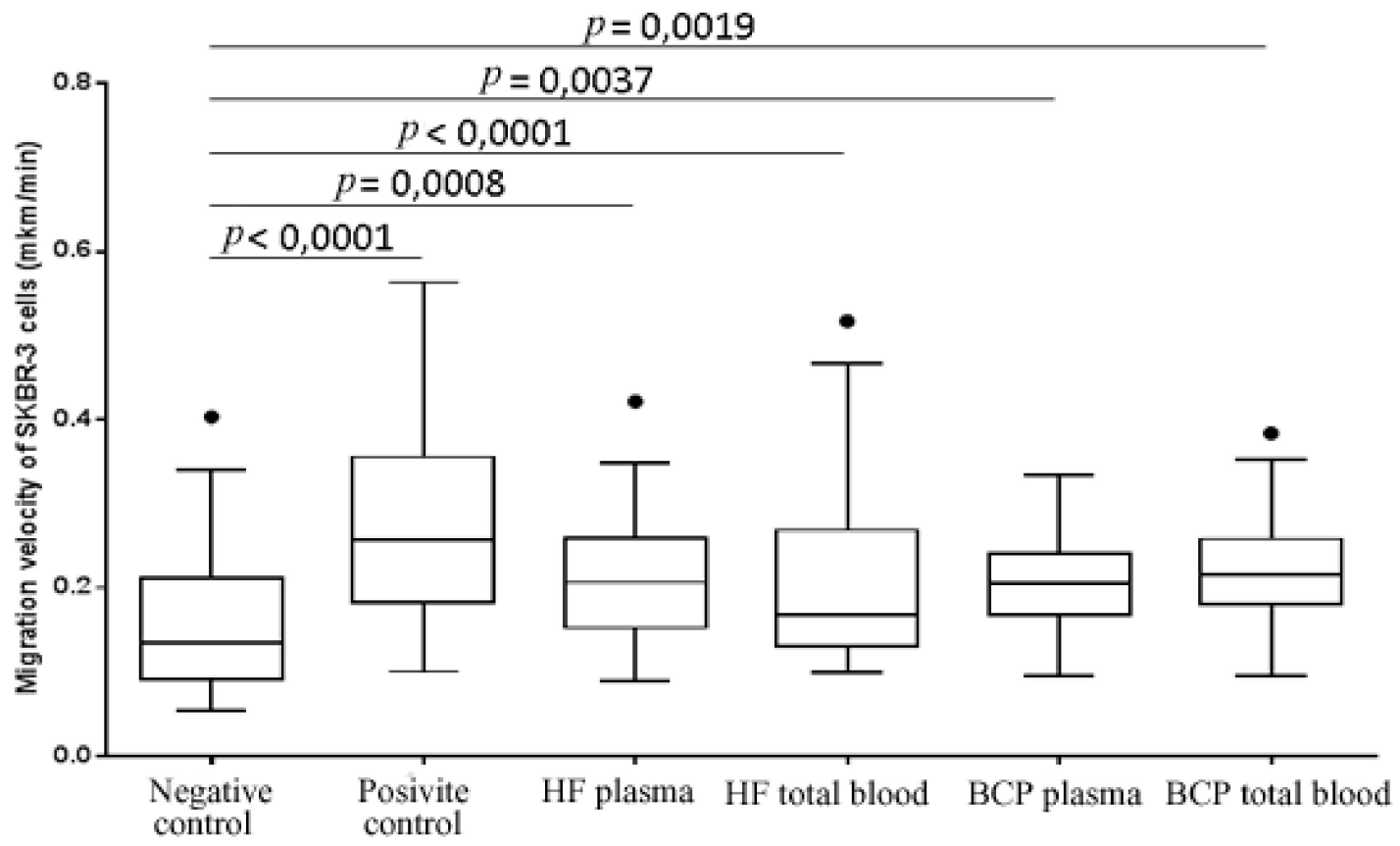

Figure 2. The velocity of migrating MCF10A (A) and SKBR-3 (B) cells under specified conditions. Results are presented as Tukey box plots. Median (-) velocity with $25-75 \%$ ( $\square$ ) and non-outlier range bars are indicated.

Negative controls include cells without HS and EGF for MCF10A and FCS for SKBR-3. Positive controls include cells with HS and with EGF for MCF10A and with FCS for SKBR-3. Each experiment was repeated 4 to 7 times. The significance of cell stimulation was evaluated by comparison with the corresponding negative control. NS - non-significant. 
SKBR-3 tumor cells in DMEM supplemented with 10\% FCS have fibroblast-like shapes. These cells, even in dense culture and inside groups move actively. The maximal increase in motile cell numbers and the highest migration rates were observed in cells supplemented with 10\% FCS, without exosomes (Table 4). Cell washing with DMEM without serum led to a significant weakening in cell migration, suggesting FCS had the greatest impact on SKBR-3 cell motility. The addition of exosomes from HFs and BCPs to control cells without calf serum contributed to the increase in the number of single tumor cells capable of promoting the migration by 2.5-3 times, but no statistically significant differences have been observed (Table 4, Figure S1B). Furthermore, we found that any exosomes (from plasma and total blood of HFs or BCPs), significantly stimulated the velocity of movement of cancer cells. The lower effect on the increase in cell velocity had the addition of total blood exosomes from HFs (Figure 2B). In particular, the median migration velocity of SKBR-3 cells after adding exosomes from HF plasma, BCP plasma and BCP total blood were; $0.2062 \mu \mathrm{m} / \mathrm{min}, 0.2045 \mu \mathrm{m} / \mathrm{min}$ and $0.2162 \mu \mathrm{m} / \mathrm{min}$, respectively. After adding exosomes from $\mathrm{HF}$ total blood, the rate was $0.1673 \mu \mathrm{m} / \mathrm{min}$ (Figure $2 \mathrm{~B}$, Figure S1B).

\subsection{Mass-spectrometry Analysis of the Exosomal Proteome Reveals Proteins Associated with Cell Motility and} Invasiveness

After 1D SDS-PAGE exosomal protein separation (Figure S2), the whole lane was cut into 25 bands of about $2 \mathrm{~mm}$ each. Followed by in-gel trypsin digestion, the peptides were extracted from each band and then loaded to MALDI-TOF/TOF mass spectrometer for protein identification, respectively.

In total, 111 and 146 proteins were identified with high reliability $(\mathrm{P}<0.05)$ by MALDI-TOF mass-spectrometry, in exosomes from HF and BCP blood, respectively. Of these, 34 were common between groups (Figure 3, Table 5). The proportions of proteins detected only in the total blood exosomes of HFs and BCPs were $24 \%$ and $42 \%$, respectively (Tables 6 and 7 ). Approximately $45 \%$ of identified exosomal proteins were previously discovered in other studies, using mass spectrometry and annotated in the Exocarta database (www.exocarta.org) (Tables S1 and S2).

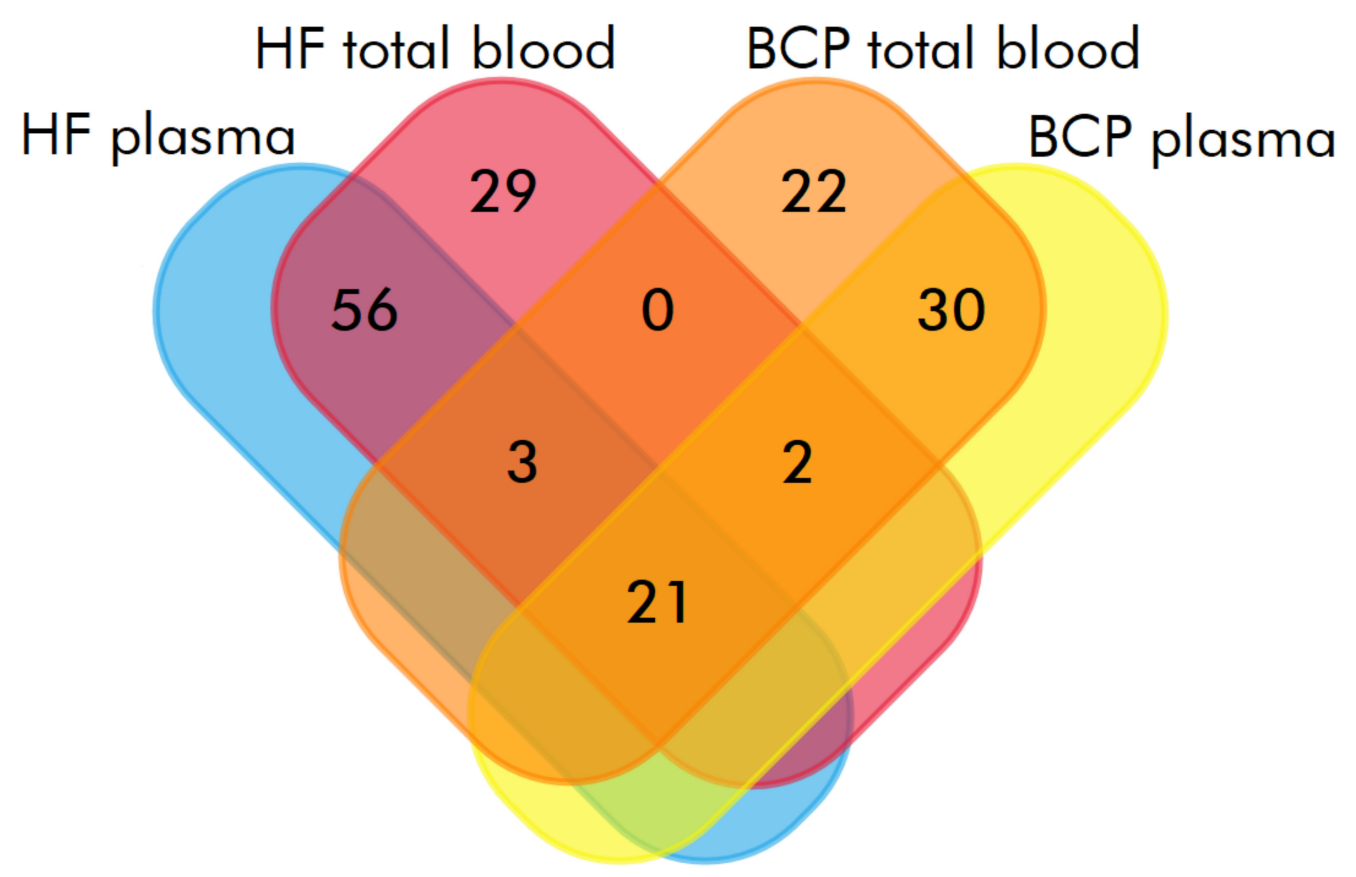

Figure 3. Venn-Euler diagram of proteins in exosomes from HF and BCP blood. 
Table 5. Universal Exosomal Proteins Identified in the Blood of HFs and BCPs*.

\begin{tabular}{|c|c|c|c|c|}
\hline Uniprot ID & Protein Name & Gene Name & ExoCarta & Score \\
\hline O14672 & $\begin{array}{l}\text { Disintegrin and metalloproteinase } \\
\text { domain-containing protein } 10\end{array}$ & ADAM10 & + & 60 \\
\hline O43399 & Tumor protein D54 & TPD52L2 & + & 61 \\
\hline O75531 & Barrier-to-autointegration factor & BANF1 & + & 57 \\
\hline P00738 & Haptoglobin & $\mathrm{HP}$ & + & 74 \\
\hline P00739 & Haptoglobin-related protein & HPR & - & 60 \\
\hline P01024 & Complement C3 & $\mathrm{C} 3$ & + & 137 \\
\hline P01834 & Ig kappa chain $C$ region & IGKC & + & 59 \\
\hline P01859 & Ig gamma- 2 chain $C$ region & IGHG2 & + & 59 \\
\hline P02647 & Apolipoprotein A-I & APOA1 & + & 176 \\
\hline P02671 & Fibrinogen alpha chain & FGA & + & 57 \\
\hline P02675 & Fibrinogen beta chain & FGB & + & 60 \\
\hline P02679 & Fibrinogen gamma chain & FGG & + & 67 \\
\hline P02750 & Leucine-rich alpha-2-glycoprotein & LRG & - & 60 \\
\hline P02760 & Alpha-1-microglycoprotein & AMBP & + & 60 \\
\hline P02765 & Alpha-2-HS-glycoprotein & AHSG & + & 60 \\
\hline P02766 & Transthyretin & TTR & + & 58 \\
\hline P02768 & Serum albumin & ALB & + & 149 \\
\hline P02787 & Serotransferrin & $\mathrm{TF}$ & - & 137 \\
\hline P02790 & Hemopexin & HPX & + & 60 \\
\hline P04114 & Apolipoprotein B-100 & APOB & + & 56 \\
\hline P06396 & Gelsolin & GSN & - & 60 \\
\hline P06727 & Apolipoprotein A-IV & APOA4 & + & 60 \\
\hline P08962 & CD63 antigen & CD63 & + & 60 \\
\hline P10909 & Clusterin & CLU & + & 60 \\
\hline P21926 & CD9 antigen & CD9 & + & 60 \\
\hline P25063 & Signal transducer CD24 & CD24 & + & 60 \\
\hline P60033 & CD81 antigen & CD81 & + & 60 \\
\hline P68871 & Hemoglobin subunit beta & HBB & + & 72 \\
\hline Q08426 & Peroxisomalbifunctional enzyme & EHHADH & + & 56 \\
\hline Q13424 & Alpha-1-syntrophin & SNTA1 & + & 60 \\
\hline Q15776 & Zinc finger protein with KRAB and SCAN domains 8 & ZKSCAN8 & - & 56 \\
\hline Q8TES7 & Fas-binding factor 1 & FBF1 & + & 56 \\
\hline Q96PX6 & Coiled-coil domain-containing protein $85 \mathrm{~A}$ & CCDC85A & - & 64 \\
\hline Q9H6Z4 & Ran-binding protein 3 & RANBP3 & + & 56 \\
\hline
\end{tabular}

Table 6. Unique Exosomal Proteins Identified in Total Blood of HFs.

\begin{tabular}{ccccc}
\hline Uniprot ID & Protein Name & Gene Name & ExoCarta & Score \\
\hline A6NCL7 & Ankyrin repeat domain-containing protein 33B & ANKRD33B & - & 57 \\
A8MU93 & Uncharacterizedprotein C17orf100 & C17orf100 & - & 56 \\
O15054 & Lysine-specific demethylase 6B & KDM6B & + & 58 \\
O60832 & H/ACA ribonucleoprotein complex subunit 4 & DKC1 & + & 56 \\
O95602 & DNA-directed RNA polymerase I subunit RPA1 & POLR1A & - & 57 \\
P02545 & Prelamin-A/C & LMNA & + & 59 \\
P05976 & Myosin light chain 1/3, skeletal muscle isoform & MYL1 & + & 56 \\
P26440 & Isovaleryl-CoA dehydrogenase, mitochondrial & IVD & - & 57 \\
P31327 & Carbamoyl-phosphate synthase [ammonia], & CPS1 & + & 62 \\
P31749 & mitochondrial & AKT1 & + & 62 \\
\hline
\end{tabular}


Table 6. Cont.

\begin{tabular}{ccccc}
\hline Uniprot ID & Protein Name & Gene Name & ExoCarta & Score \\
\hline P48506 & Glutamate-cysteine ligase catalytic subunit & GCLC & - & 56 \\
P49748 & Very long-chain specific acyl-CoA dehydrogenase, & ACADVL & - & 56 \\
P49763 & mitochondrial & Placenta growth factor & PGF & 56 \\
P53674 & Beta-crystallin B1 & CRYBB1 & - & 80 \\
Q11201 & CMP-N-acetylneuraminate-beta- & ST3GAL1 & - & 58 \\
Q49A33 & galactosamide-alpha-2,3-sialyltransferase 1 & ZNF876P & - & 56 \\
Q49MG5 & Putative zinc finger protein 876 & MAP9 & - & 58 \\
Q504T8 & Microtubule-associated protein 9 & MIDN & - & 56 \\
Q69YQ0 & Midnolin & SPECC1L & + & 68 \\
Q6P1J9 & Cytospin-A & CDC73 & 60 \\
Q6ZS02 & Putative GED domain-containing protein DNM1P46 & DNM1P46 & - & 57 \\
Q7Z553 & MAM domain-containing & MDGA2 & - & 56 \\
Q86VE0 & Myb-related transcription factor, partner of profilin & MYPOP & - & 57 \\
Q8N8C0 & Zinc finger protein 781 & ZNF781 & - & 65 \\
Q9HBI5 & Uncharacterized protein C3orf14 & C3orf14 & - & 56 \\
Q9P2W7 & Galactosylgalactosylxylosylprotein & B3GAT1 & - & 56 \\
Q9UK05 & 3-beta-glucuronosyltransferase 1 & GDF2 & + & 59 \\
\hline
\end{tabular}

Table 7. Unique Exosomal Proteins Identified in Total Blood of BCPs.

\begin{tabular}{ccccc}
\hline UniprotID & Protein Name & Gene Name & Exocarta & Score \\
\hline A0A0B4J1X5 & Immunoglobulin heavy variable 3-74 & IGHV3-74 & - & 56 \\
A0A1B0GVM6 & Uncharacterized protein C11orf97 & C11orf97 & - & 56 \\
A0A589 & T cell receptor beta variable & TRBV4-3 & - & 56 \\
O14543 & Suppressor of cytokine signaling 3 & SOCS3 & - & 63 \\
O15018 & PDZ domain-containing protein 2 & PDZD2 & - & 57 \\
O15020 & Spectrin beta chain, non-erythrocytic 2 & SPTBN2 & + & 66 \\
O15083 & ERC protein 2 & ERC2 & - & 56 \\
O60397 & Putative cytochrome c oxidase subunit 7A3, & COX7A2P2 & - & 58 \\
O75635 & mitochondrial & SERPINB7 & - & 56 \\
O95243 & Serpin B7 & MBD4 & - & 56 \\
O95613 & Methyl-CpG-binding domain protein 4 & PCNT & - & 71 \\
P02538 & Pericentrin & KRT6A & + & 62 \\
P04217 & Keratin, type II cytoskeletal 6A & A1BG & + & 128 \\
P04259 & Alpha-1B-glycoprotein & KRT6B & + & 58 \\
P04264 & Keratin, type II cytoskeletal 6B & KRT1 & - & 81 \\
P09601 & Keratin, type II cytoskeletal 1 & HMOX1 & - & 56 \\
P13497 & Heme oxygenase 1 & BMP1 & - & 60 \\
P16233 & Bone morphogenetic protein 1 & PNLIP & - & 56 \\
P35527 & Pancreatic triacylglycerol lipase & KRT9 & + & 57 \\
P48167 & Keratin, type I cytoskeletal 9 & GLRB & - & 56 \\
P49761 & Glycine receptor subunit beta & CLK3 & - & 56 \\
P50440 & Dual specificity protein kinase CLK3 & GATM & - & 56 \\
P55199 & Glycine amidinotransferase, mitochondrial & ELL & - & 56 \\
P62987 & RNA polymerase II elongation factor ELL & UBA52 & - & 57 \\
Q13522 & Ubiquitin-60S ribosomal protein L40 & PPM1A & + & 56 \\
Q13535 & Protein phosphatase 1A & ATR & - & 58 \\
\hline
\end{tabular}


Table 7. Cont.

\begin{tabular}{|c|c|c|c|c|}
\hline UniprotID & Protein Name & Gene Name & Exocarta & Score \\
\hline Q14005 & Pro-interleukin-16 & IL16 & - & 56 \\
\hline Q14320 & Protein FAM50A & FAM50A & - & 61 \\
\hline Q14571 & Inositol 1,4,5-trisphosphate receptor type 2 & ITPR2 & + & 67 \\
\hline Q14624 & Inter-alpha-trypsin inhibitor heavy chain $\mathrm{H} 4$ & ITIH4 & + & 80 \\
\hline Q15024 & Exosome complex component RRP42 & EXOSC7 & + & 56 \\
\hline Q15477 & Helicase SKI2W & SKIV2L & + & 65 \\
\hline Q16775 & Hydroxyacylglutathione hydrolase, mitochondrial & HAGH & + & 56 \\
\hline Q16890 & Tumor protein D53 & TPD52L1 & - & 56 \\
\hline Q2M218 & Zinc finger protein 630 & ZNF630 & - & 80 \\
\hline Q4G0S7 & Coiled-coil domain-containing protein 152 & CCDC152 & - & 63 \\
\hline Q52M93 & Zinc finger protein 585B & ZNF585B & - & 57 \\
\hline Q5R372 & Rab GTPase-activating protein 1-like & RABGAP1L & - & 56 \\
\hline Q5VWM5 & PRAME family member $9 / 15$ & PRAMEF9 & - & 58 \\
\hline Q68J44 & Dual specificity phosphatase DUPD1 & DUPD1 & - & 57 \\
\hline Q6P1J6 & Phospholipase B1, membrane-associated & PLB1 & - & 56 \\
\hline Q7L5N7 & Lysophosphatidylcholine acyltransferase 2 & LPCAT2 & - & 56 \\
\hline Q7L5Y9 & E3 ubiquitin-protein transferase MAEA & MAEA & - & 56 \\
\hline Q7RTT3 & Putative protein SSX9 & SSX9P & - & 189 \\
\hline Q8IUS5 & Epoxide hydrolase 4 & EPHX4 & - & 57 \\
\hline Q8IYA6 & Cytoskeleton-associated protein 2-like & CKAP2L & - & 65 \\
\hline Q8IYE0 & Coiled-coil domain-containing protein 146 & CCDC146 & - & 57 \\
\hline Q8NDD1 & Uncharacterizedprotein C1orf131 & C1orf131 & - & 56 \\
\hline Q8NEQ6 & Steroid receptor-associated and regulated protein & SRARP & - & 59 \\
\hline Q8WXR4 & Myosin-IIIb & MYO3B & + & 56 \\
\hline Q8WXS5 & $\begin{array}{l}\text { Voltage-dependent calcium channel gamma-8 } \\
\text { subunit }\end{array}$ & CACNG8 & - & 63 \\
\hline Q92622 & $\begin{array}{l}\text { Run domain Beclin-1-interacting and cysteine-rich } \\
\text { domain-containing protein }\end{array}$ & RUBCN & - & 56 \\
\hline Q92624 & Amyloid protein-binding protein 2 & APPBP2 & - & 61 \\
\hline Q99623 & Prohibitin-2 & PHB2 & + & 74 \\
\hline Q9H497 & Torsin-3A & TOR3A & + & 63 \\
\hline Q9H4Q4 & PR domain zinc finger protein 12 & PRDM12 & - & 56 \\
\hline Q9H9E3 & Conserved oligomeric Golgi complex subunit 4 & COG4 & - & 56 \\
\hline Q9NQG6 & Mitochondrial dynamics protein MID51 & MIEF1 & - & 60 \\
\hline Q9NSD9 & Phenylalanine-tRNA ligase beta subunit & FARSB & + & 56 \\
\hline Q9NZJ4 & Sacsin & SACS & - & 56 \\
\hline Q9NZU7 & Calcium-binding protein 1 & CABP1 & - & 56 \\
\hline Q9Y4E5 & E3 SUMO-protein ligase ZNF451 & ZNF451 & + & 69 \\
\hline
\end{tabular}

Using the dbDEPC 3.0 database (database of Differently Expressed Proteins in Human Cancer) [17] it was found that in plasma exosomes from BCPs, 49 (66\%) proteins were associated with malignant neoplasms of which 38 (51\%) were associated with the development of breast cancer (Figure 4A). It should be noted that in total blood exosomes from BCPs $86(59 \%)$ proteins associated with malignant neoplasms was revealed of which $51(35 \%)$ were associated with the development of breast cancer (Figure 4B). Thus, breast cancer-associated proteins in plasma exosomes were detected more frequently than in total blood exosomes ( $51 \%$ vs. $35 \%$ ), what can be explained by the intensive study of the composition of plasma exosomes and the recently discovered phenomenon of exosomes associated with blood cells.

Hyper- and hypo-expressed proteins associated with breast cancer development were equally represented in the composition of total blood exosomes (39\% and $43 \%$ hyper- and hypo-expressed proteins, respectively), however, hypo-expressed proteins ( $47 \%$ vs. $29 \%$ hyper-expressed proteins) predominate in plasma exosomes (Figure 4). 
Functional enrichment analysis was performed using FunRich software for all exosomal proteins, revealing enriched GO terms for cellular components, molecular functions and biological processes (Figure 5). It was revealed that in exosomes from BCP blood, the share of cytoplasmic proteins increased in comparison to exosomes from HF blood (55\% vs. 47\%) (Figure 5A). The functions of 20\% of exosomal proteins from HF blood and 25\% of exosomal proteins from BCP blood were not clear; however, with the development of pathology, the portion of proteins with catalytic activity and transporter activity slightly increased (Figure 5B). Common exosomal proteins from HF and BCP blood exosomes were mainly involved in cell communication ( $20 \%$ and $16 \%$, respectively), signal transduction ( $22 \%$ and $17 \%$, respectively), and regulation of nucleoside, nucleotide, and nucleic acids metabolism (15\% and $10 \%$, respectively). It should also be noted that proteins involved in protein metabolism and transport proteins were found in exosomes from BCP blood more frequently (Figure 5C).

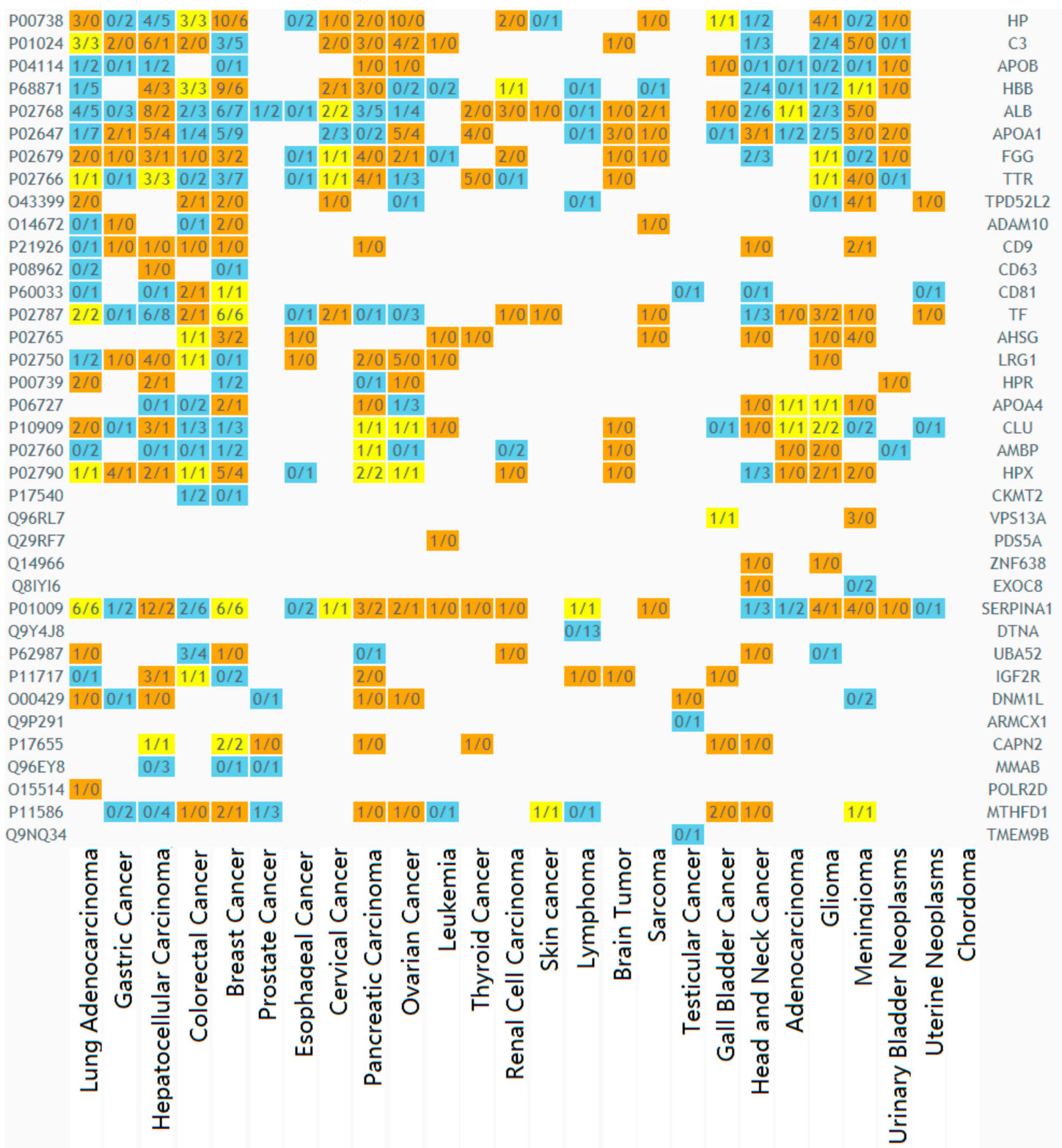

A

Figure 4. Cont. 


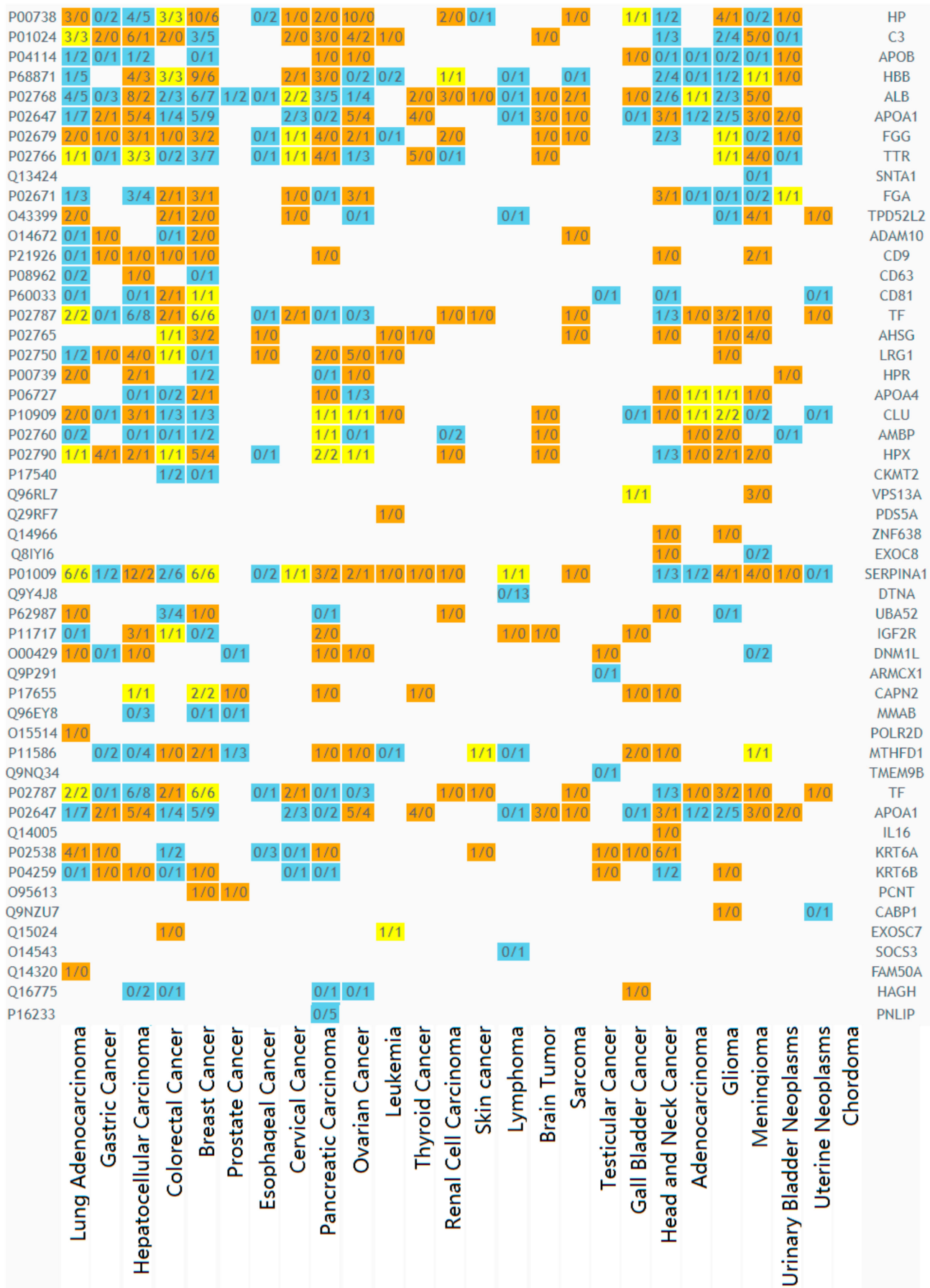

B

Figure 4. Heat map generated by dbDEPC 3.0 [17] from exosomal proteins from BCP blood, associated with different cancer types; plasma exosomes (A), total blood exosomes (B). Orange means that the number of the studies identified this protein as up-regulated is more than the number of the studies identified the protein as down-regulated; blue means that the number of the studies identified this protein as up-regulated is less than the number of the studies identified protein as down-regulated; yellow means that the number of the studies identified the protein as up-regulated is equal to the number of the studies identified protein as down-regulated. 


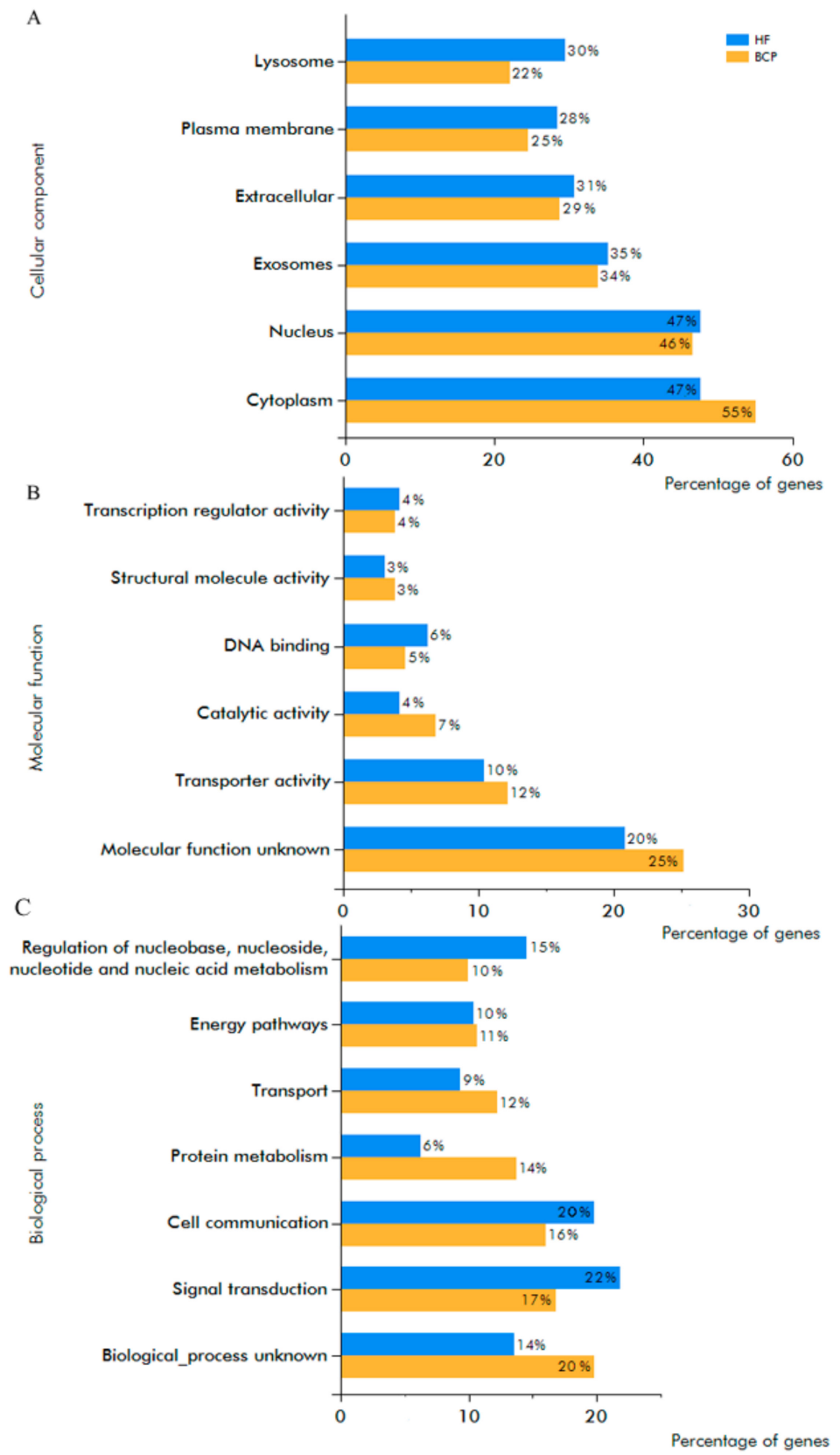

Figure 5. GO analysis of exosomal proteins from HF and BCP blood. Proteins were classified by cellular component (A), molecular function (B) and biological processes (C).

A literature analysis of exosomal proteins revealed that $51(46 \%)$ were associated with invasion-associated functions in total blood exosomes from HFs, and $55(38 \%)$ such proteins were detected in total BCP blood exosomes, 19 (22\%) of which were common to both groups (Figure 6). Notably, in the proteome of HF exosomes, several proteins were engaged with invasion suppression (AIM2, APOE, BARD1, GDF2, PIP4K2B and PLEKHA7) while only two such proteins (IGF2R and KRT1) were revealed in exosomes from BCP blood. Furthermore, 25 (23\%) and $21(14 \%)$ proteins involved in the regulation of cell migration were identified in HF and BCP total blood exosomes, respectively (Figure 7). GO analysis using QuickGO revealed that four (APOE, AKT1, GDF2 and BARD1) out of 16 unique proteins from exosomes from HF blood were involved in the negative migration regulation of endothelial and lymphocytic cells [25-27]. Thus, it appeared that proteomic profiles of exosomes from HF blood were enriched by proteins for the negative regulation of cell migration and invasion. 


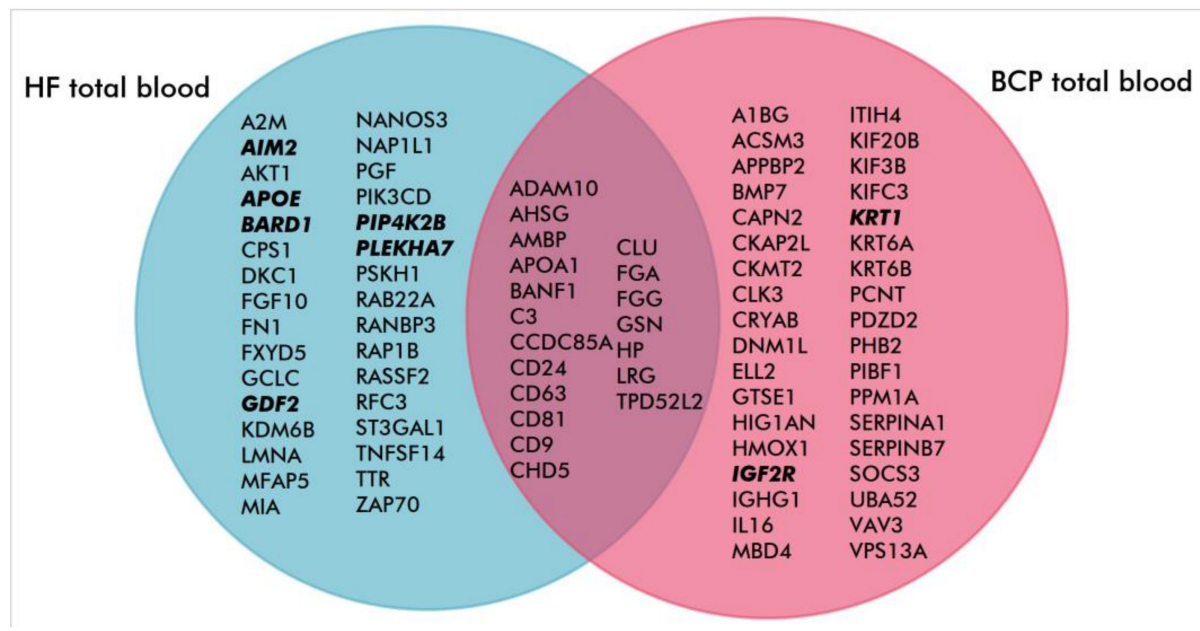

Figure 6. Venn-Euler diagram of exosomal proteins associated with invasion (blood from HFs and BCPs). Proteins that suppress invasion are in bold.

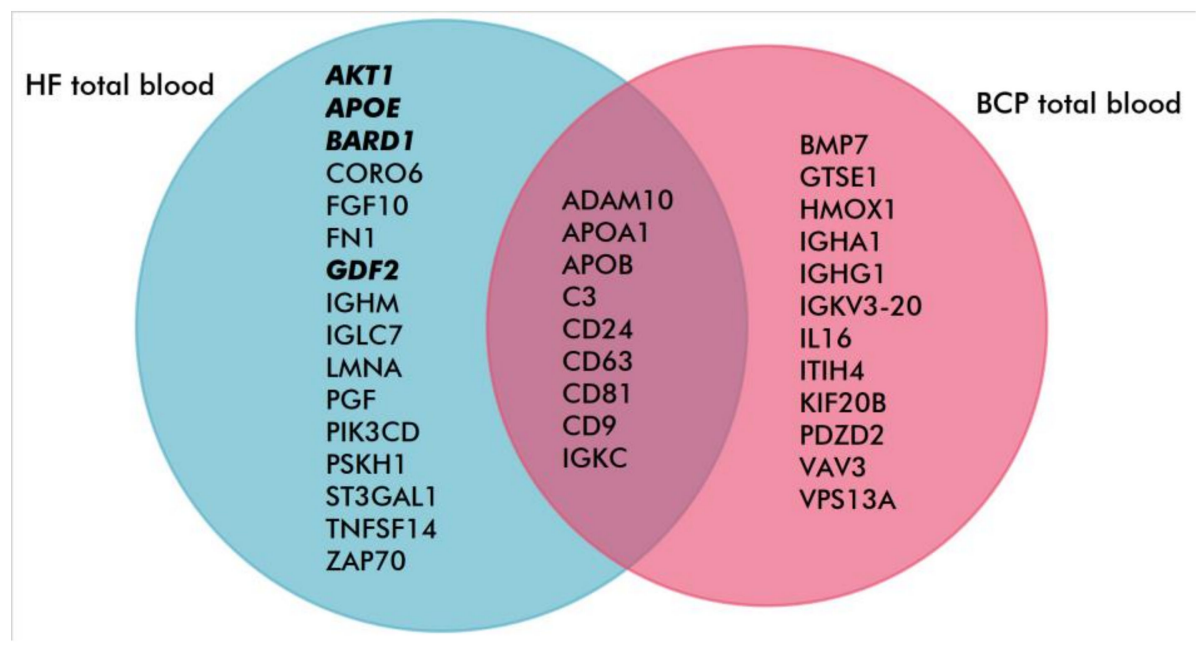

Figure 7. Venn-Euler diagram of exosomal proteins associated with cell migration (blood from HFs and BCPs). Proteins that suppress migration are in bold.

\subsection{ADAM-10 Expression Levels are Increased in Exosomes from BCP Luminal Subtype Blood}

ADAM-10 is the most common exosomal metalloproteinase involved in the ectodomain shedding of various substrates, including growth factor receptors, adhesion receptors and cadherins [28]. This leads to increased cell motility and, as a consequence, an increase in the metastatic potential of tumor cells [29].

Since CD9 and CD24 were the most represented receptors on the surface of plasma and total blood exosomes, levels of the tetraspanin-associated metalloproteinase, ADAM-10 were estimated for CD9 and CD24-positive exosomes. The expression of ADAM-10 was significantly increased in subpopulations of CD9-positive exosomes, from plasma and total blood of luminal subtype BCPs, when compared with HF (the difference was 1.8 and 1.3 fold, respectively), and triple-negative subtype $\mathrm{BCP}$ samples (the difference was 1.6 and 1.2 fold, respectively). Moreover, in this subpopulation from total blood, ADAM-10 expression in BCPs with a luminal subtype was significantly reduced (1.5 times), when compared with plasma exosomes (Table 8). At the same time, analysis of ADAM-10 expression in CD24-positive exosomes from plasma and total blood did not reveal a significant difference of metalloproteinase levels between HF and BCP (Table 8). 
Table 8. Expression of CD9 and CD24 on the Surface of ADAM-10 Positive Exosomes from Plasma and Total Blood of HFs and BCPs.

\begin{tabular}{|c|c|c|c|}
\hline \multicolumn{2}{|c|}{ 4. Source of Exosomes } & \multirow{2}{*}{$\begin{array}{c}\text { CD9+ } \\
844 \pm 99 \\
804 \pm 79 \\
\end{array}$} & \multirow{2}{*}{$\begin{array}{c}\text { CD24+ } \\
884 \pm 124 \\
920 \pm 91\end{array}$} \\
\hline HFs & $\begin{array}{c}\text { Plasma } \\
\text { Total blood }\end{array}$ & & \\
\hline $\begin{array}{c}\text { BCPs } \\
\text { Luminal subtype }\end{array}$ & $\begin{array}{c}\text { Plasma } \\
\text { Total blood }\end{array}$ & $\begin{array}{l}1531 \pm 162 * \\
1026 \pm 100^{*}\end{array}$ & $\begin{array}{c}926 \pm 94 \\
1103 \pm 99\end{array}$ \\
\hline $\begin{array}{c}\text { BCPs } \\
\text { Triple-negative subtype }\end{array}$ & $\begin{array}{c}\text { Plasma } \\
\text { Total blood }\end{array}$ & $\begin{array}{l}962 \pm 88 \\
862 \pm 69\end{array}$ & $\begin{array}{l}908 \pm 109 \\
969 \pm 106\end{array}$ \\
\hline
\end{tabular}

\section{Discussion}

Interactions between cancer cells and their microenvironments are important for tumor development [8]. Communications between tumor and non-malignant cells can be performed by exosomes, which transfer molecules such as mRNAs, microRNAs and proteins between cells $[8,30]$. It should be noted that the majority of studies were performed with exosomes from cell culture. However, the pool of exosomes that circulate in the blood (blood circulating exosomes) is comprised of exosomes secreted by leukocytes, erythrocytes, thrombocytes, and endotheliocytes (i.e., either by hemic cells or cells interacting with the blood), as well as tissue cells, such as fibroblasts, epithelial cells and tumor cells [31,32]. Similarly noteworthy is the two fractions of exosomes in the blood: cell-free plasma exosomes and blood cell-surface-associated exosomes [11]. Undoubtedly, exosome transport is provided not only by the liquid blood fraction but by blood cells as well. However, the interactions of normal and metastatic tumor cells with cell-free exosomes and blood cell-associated exosomes have not yet been studied.

Here, we demonstrated that plasma exosomes morphologically resemble total blood exosomes and that both pools of exosomes are positive for CD24, CD63, and CD9 markers. However, the proportion of blood cell-associated exosomes in breast cancer is decreased, in comparison with the healthy state. Since most exosomes in the blood of cancer patients are of non-tumor origins, the reason for this decrease remains unclear. This phenomenon may be associated with an increased affinity of exosomes for blood cells, or reflect true decreases in exosome levels on the blood cell surface membrane.

One of the reasons for decreases in exosome levels on the surface of BCP blood cells may be the increased activity of sheddases directly interacting not only with extracellular matrix proteins but with membrane receptors and cell adhesion molecules to target cells [33].

Since exosomal surfaces contain CD9 and CD24 receptors, the level of tetraspanin-associated metalloproteinase ADAM-10 was estimated for CD9 and CD24-positive exosomes. ADAM-10 levels were significantly increased in subpopulations of CD9-positive exosomes isolated from the plasma and total blood fractions of patients with luminal breast cancer, as compared with HFs and triple-negative subtype BCPs. At the same time, there were no significant changes in ADAM-10 expression levels on CD24-positive exosomes. These results correlate with data [34] suggesting that the inclusion of the mature form of ADAM-10 into exosomes, and the proteolytic activity of this sheddase is regulated by the tetraspanins, CD9, CD81 and CD82. Thus, our data suggest that increased ADAM-10 expression levels on the surface of exosomes reduce their binding to blood cells [28], thereby increasing concentrations of cell-free exosomes, which in turn allows exosomes to act as intermediaries in providing intercellular communication through horizontal transfer of RNA and proteins, affecting the development of both primary neoplasms and distant metastases.

In addition to the effects of cancer exosomes on healthy tissue cells, the effects of exosomes secreted by normal tissue cells on tumor cells are also of importance in disease pathogenesis. For example, cells from a growing tumor are affected by exosomes secreted by normal cells in the surrounding stroma, and circulating tumor cells are affected by plasma exosomes of different origins. Therefore, we 
sought to examine the effects of plasma exosomes and total blood exosomes from HF and BCP blood on cell migration, a key step in metastasis. We found that exosomes from BCP total blood significantly stimulate non-tumor cell migration. This effect manifests itself as an increased number of motile cells; however, we did not observe any influence of exosomes on migratory cell velocity. Exosomes from plasma and total blood, obtained from both HFs and BCPs, stimulated the migration velocity of tumor cell but did not affect the amount of the migrating cells. Total blood exosomes from HFs had the least effect on the migration velocity.

To unravel molecular regulatory roles behind blood exosome-mediated migration and invasion, protein profiling on plasma and total blood exosomes was performed. Currently, there are few reports on the proteomic analysis of exosomes, especially for plasma exosomes in breast cancer, when compared to other types of cancer [35,36] and a dearth of data on proteomic profiles in blood cell-bound exosomes. Technical difficulties in blood exosome proteomics are primarily associated with the heterogeneity of the composition of circulating vesicles.

Consistent with previous studies [5,37] our analysis showed that the majority of proteins from cell-free and total blood exosomes were of cytoplasmic origins. An increase in proteins involved in protein metabolism, and proteins with transport and catalytic activities in the blood exosomes of BCPs, suggest a significant role of exosomes in the development of malignant neoplasms. We did not find protein inhibitors of cell migration in these exosomes that correlated with the phenomena of stimulation of non-tumor MCF10A cells migrations. At the same time, the presence of cell migration inhibitors (APOE, AKT1, BARD1, GDF2) in exosomes from blood HFs accompanied by low stimulating effects on the migration velocity of tumor cells. Thus, the analysis of protein composition in exosomes complements their biogenesis and functional roles in cancer development.

\section{Conclusions}

In conclusion, this study indicates that the increased concentration of cell-free exosomes in the blood from BCPs correlated with increased exosomal ADAM-10 expression; however, total blood exosomes contain more malignant neoplasm-associated proteins than plasma exosomes. Exosomes from the total blood of BCPs were enriched by proteins with catalytic, transporter and protein metabolism activities. In this first proteomic profiling study of exosomes from plasma and total blood from HFs and BCPs, exosomes from HF total blood were enriched for proteins inhibiting cell migration and invasion, with low stimulating activity on the migration velocity of cancer cells. Follow-up studies are required to understand protein inhibitors of cell migration (i.e., APOE, AKT1, BARD1 and GDF2) and their usefulness in developing new anti-metastatic therapies.

Supplementary Materials: The following are available online at http://www.mdpi.com/2218-273X/10/4/495/s1, Figure S1: title, Figure S2: title, Table S1: title, Table S2: title

Author Contributions: Conceptualization, S.T.; investigation, S.T., O.T., E.O., K.P., A.G., N.Y. and A.A.; writing, Y.T., A.A. and S.T. All authors reviewed and revised the manuscript. All authors have read and agreed to the published version of the manuscript.

Funding: This work was supported by the Russian Foundation for Basic Research and Government of Novosibirsk region of the Russian Federation, grant 18-415-540012.

Acknowledgments: The authors thank Sergey Vasin (KD Systems and Instruments) for technical assistance.

Conflicts of Interest: The authors declare no conflict of interest.

\section{References}

1. Osaki, M.; Okada, F. Exosomes and their role in cancer progression. Yonago Acta Med. 2019, 62, $182-190$. [CrossRef]

2. Whiteside, T.L. The potential of tumor-derived exosomes for noninvasive cancer monitoring: An update. Expert Rev. Mol. Diagn. 2018, 18, 1029-1040. [CrossRef] [PubMed] 
3. Lawson, J.; Dickman, C.; Towle, R.; Jabalee, J.; Javer, A.; Garnis, C. Extracellular vesicle secretion of miR-142-3p from lung adenocarcinoma cells induces tumor promoting changes in the stroma through cell-cell communication. Mol. Carcinog. 2019, 58, 376-387. [CrossRef] [PubMed]

4. Li, Z.; Tao, Y.; Wang, X.; Jiang, P.; Li, J.; Peng, M.; Zhang, X.; Chen, K.; Liu, H.; Zhen, P.; et al. Tumor-secreted exosomal miR-222 promotes tumor progression via regulating P27 expression and re-localization in pancreatic cancer. Cell Physiol. Biochem. 2018, 51, 610-629. [CrossRef] [PubMed]

5. Harris, D.A.; Patel, S.H.; Gucek, M.; Hendrix, A.; Westbroek, W.; Taraska, J.W. Exosomes released from breast cancer carcinomas stimulate cell movement. PLoS ONE 2015, 10, e0117495. [CrossRef] [PubMed]

6. Li, R.; Wang, Y.; Zhang, X.; Feng, M.; Ma, J.; Li, J.; Yang, X.; Fang, F.; Xia, Q.; Zhang, Z.; et al. Exosome-mediated secretion of LOXL4 promotes hepatocellular carcinoma cell invasion and metastasis. Mol. Cancer 2019, 18, e18. [CrossRef]

7. Li, Z.; Zeng, C.; Nong, Q.; Long, F.; Liu, J.; Mu, Z.; Chen, B.; Wu, D.; Wu, H. Exosomal leucine-rich-alpha2-glycoprotein 1 derived from non-small-cell lung cancer cells promotes angiogenesis via TGF- $\beta$ signal pathway. Mol. Ther. Oncolytics 2019, 14, 313-322. [CrossRef]

8. Groza, M.; Zimta, A.A.; Irimie, A.; Achimas-Cadariu, P.; Cenariu, D.; Stanta, G.; Berindan-Neagoe, I. Recent advancements in the study of breast cancer exosomes as mediators of intratumoral communication. J. Cell. Physiol. 2020, 235, 691-705. [CrossRef]

9. Mathieu, M.; Martin-Jaular, L.; Lavieu, G.; Théry, C. Specificities of secretion and uptake of exosomes and other extracellular vesicles for cell-to-cell communication. Nat. Cell Biol. 2019, 21, 9-17. [CrossRef]

10. Buzas, E.I.; Toth, E.A.; Sodar, B.W.; Szabo-Taylor, K.E. Molecular interactions at the surface of extracellular vesicles. Semin. Immunopathol. 2018, 40, 453-464. [CrossRef]

11. Tamkovich, S.; Tutanov, O.; Efimenko, A.; Grigor'eva, A.; Ryabchikova, E.; Kirushina, N.; Vlassov, V.; Tkachuk, V.; Laktionov, P. Blood circulating exosomes contain distinguishable fractions of free and cell-surface-associated vesicles. Curr. Mol. Med. 2019, 19, 273-285. [CrossRef] [PubMed]

12. Tamkovich, S.N.; Bakakina, Y.S.; Tutanov, O.S.; Somov, A.K.; Kirushina, N.A.; Dubovskaya, L.V.; Volotovski, I.D.; Laktionov, P.P. Proteome analysis of circulating exosomes in health and breast cancer. Russ. J. Bioorg. Chem. 2017, 43, 126-134. [CrossRef]

13. Yunusova, N.V.; Patysheva, M.R.; Molchanov, S.V.; Zambalova, E.A.; Grigor'eva, A.E.; Kolomiets, L.A.; Ochirov, M.O.; Tamkovich, S.N.; Kondakova, I.V. Metalloproteinases at the surface of small extrcellular vesicles in advanced ovarian cancer: Relationships with ascites volume and peritoneal canceromatosis index. Clin. Chim. Acta 2019, 494, 116-122. [CrossRef] [PubMed]

14. Tamkovich, S.N.; Tutanov, O.S.; Serdukov, D.S.; Belenikin, M.S.; Shlikht, A.G.; Kirushina, N.A.; Voytsitskiy, V.E.; Tsentalovich, Y.P.; Tkachuk, V.A.; Laktionov, P.P. Protein content of circulating nucleoprotein complexes. Adv. Exp. Med. Biol. 2016, 924, 133-136.

15. Pathan, M.; Keerthikumar, S.; Chisanga, D.; Alessandro, R.; Ang, C.S.; Askenase, P.; Batagov, A.O.; Benito-Martin, A.; Camussi, G.; Clayton, A.; et al. A novel community driven software for functional enrichment analysis of extracellular vesicles data. J. Extracell. Vesicles 2017, 6, e1321455. [CrossRef]

16. Binns, D.; Dimmer, E.; Huntley, R.; Barrell, D.; O’Donovan, C.; Apweiler, R. QuickGO: A web-based tool for gene ontology searching. Bioinformatics 2009, 25, 3045-3046. [CrossRef]

17. Yang, Q.; Zhang, Y.; Cui, H.; Chen, L.; Zhao, Y.; Lin, Y.; Zhang, M.; Xie, L. dbDEPC 3.0: The database of differentially expressed proteins in human cancer with multi-level annotation and drug indication. Database (Oxford) 2018, 2018, bay015. [CrossRef]

18. Akers, J.C.; Ramakrishnan, V.; Nolan, J.P.; Duggan, E.; Fu, C.C.; Hochberg, F.H.; Chen, C.C.; Carter, B.S. Comparative analysis of technologies for quantifying extracellular vesicles (EVs) in clinical cerebrospinal fluids (CSF). PLoS ONE 2016, 11, e0149866. [CrossRef]

19. Van der Pol, E.; Coumans, F.A.; Grootemaat, A.E.; Gardiner, C.; Sargent, I.L.; Harrison, P.; Sturk, A.; van Leeuwen, T.G.; Nieuwland, R. Particle size distribution of exosomes and microvesicles determined by transmission electron microscopy, flow cytometry, nanoparticle tracking analysis, and resistive pulse sensing. J. Thromb. Haemost. 2014, 12, 1182-1192. [CrossRef]

20. Witwer, K.W.; Buzas, E.I.; Bemis, L.T.; Bora, A.; Lässer, C.; Lötvall, J.; Nolte-'t Hoen, E.N.; Piper, M.G.; Sivaraman, S.; Skog, J.; et al. Standardization of sample collection, isolation and analysis methods in extracellular vesicle research. J. Extracell. Vesicles 2013, 2, 20360. [CrossRef] 
21. Yanez-Mo, M.; Siljander, P.R.; Andreu, Z.; Zavec, A.B.; Borra, F.E.; Buzas, E.I.; Buzas, K.; Casal, E.; Cappello, F.; Carvalho, J.; et al. Biological properties of extracellular vesicles and their physiological functions. J. Extracell. Vesicles 2015, 4, 27066. [CrossRef] [PubMed]

22. King, J.B.; von Furstenberg, R.J.; Smith, B.J.; McNaughton, K.K.; Galanko, J.A.; Henning, S.J. CD24 can be used to isolate Lgr5+ putative colonic epithelial stem cells in mice. Am. J. Physiol. Gastrointest. Liver Physiol. 2012, 303, G443-G452. [CrossRef] [PubMed]

23. Andreu, Z.; Yanez-Mo, M. Tetraspanins in extracellular vesicle formation and function. Front. Immunol. 2014, 5, 442. [CrossRef] [PubMed]

24. Soule, H.D.; Maloney, T.M.; Wolman, S.R.; Peterson, W.D.; Brenz, R.; McGrath, C.M.; Russo, J.; Pauley, R.J.; Jones, R.F.; Brooks, S.C. Isolation and characterization of a spontaneously immortalized human breast epithelial cell line MCF-10. Cancer Res. 1990, 50, 6075-6086. [PubMed]

25. Pencheva, N.; Tran, H.; Buss, C.; Huh, D.; Drobnjak, M.; Busam, K.; Tavazoie, S.F. Convergent multi-miRNA targeting of ApoE drives LRP1/LRP8-dependent melanoma metastasis and angiogenesis. Cell 2012, 151, 1068-1082. [CrossRef] [PubMed]

26. Luoa, C.; Wang, F.; Rena, X.; Ke, T.; Xu, C.; Tang, B.; Qin, S.; Yao, Y.; Chen, Q.; Wang, Q.K. Identification of a molecular signaling gene-gene regulatory network between GWAS susceptibility genes ADTRP and MIA3/TANGO1 for coronary artery disease. Biochim. Biophys. Acta Mol. Basis Dis. 2017, 1863, 1640-1653. [CrossRef]

27. Suzuki, Y.; Ohga, N.; Morishita, Y.; Hida, K.; Miyazono, K.; Watabe, T. BMP-9 induces proliferation of multiple types of endothelial cells in vitro and in vivo. J. Cell Sci. 2010, 123, 1684-1692. [CrossRef]

28. Shimoda, M.; Khokha, R. Metalloproteinases in extracellular vesicles. Biochim. Biophys. Acta Mol. Cell Res. 2017, 1864 Pt A, 1989-2000. [CrossRef]

29. Matthews, A.L.; Noy, P.J.; Reyat, J.S.; Tomlinson, M.G. Regulation of a disintegrin and metalloproteinase (ADAM) family sheddases ADAM10 and ADAM17: The emerging role oftetraspanins and rhomboids. Platelets 2017, 28, 333-341. [CrossRef]

30. Nazarenko, I. Extracellular vesicles: Recent developments in technology and perspectives for cancer liquid biopsy. Recent Results Cancer Res. 2020, 215, 319-344.

31. Danesh, A.; Inglis, H.C.; Jackman, R.P.; Wu, S.; Deng, X.; Muench, M.O.; Heitman, J.W.; Norris, P.J. Exosomes from red blood cell units bind to monocytes and induce proinflammatory cytokines, boosting T-cell responses in vitro. Blood 2014, 123, 687-696. [CrossRef] [PubMed]

32. Minciacchi, V.R.; Freeman, M.R.; Di Vizio, D. Extracellular vesicles in cancer: Exosomes, microvesicles and the emerging role of large oncosomes. Semin. Cell Dev. Biol. 2015, 40, 41-51. [CrossRef] [PubMed]

33. Nawaz, M.; Shah, N.; Zanetti, B.R.; Maugeri, M.; Silvestre, R.N.; Fatima, F.; Neder, L.; Valadi, H. Extracellular vesicles and matrix remodeling enzymes: The emerging roles in extracellular matrix remodeling, progression of diseases and tissue repair. Cells 2018, 7, 167. [CrossRef] [PubMed]

34. Arduise, C.; Abache, T.; Li, L.; Chabanon, A.; Ludwig, A.; Mauduit, P.; Boucheix, C.; Rubinstein, E.; Le Naour, F. Tetraspanins regulate ADAM10-mediated cleavage of TNF-alpha and epidermal growth factor. J. Immunol. 2008, 181, 7002-7013. [CrossRef] [PubMed]

35. Chen, I.-H.; Xue, L.; Hsu, C.-C.; Paez, J.S.; Pan, L.; Andaluz, H.; Wendt, M.K.; Iliuk, A.B.; Zhu, J.K.; Tao, W.A. Phosphoproteins in extracellular vesicles as candidate markers for breast cancer. Proc. Natl. Acad. Sci USA 2017, 114, 3175-3180. [CrossRef] [PubMed]

36. Vardaki, I.; Ceder, S.; Rutishauser, D.; Baltatzis, G.; Foukakis, T.; Panaretakis, T. Periostin is identified as a putative metastatic marker in breast cancer-derived exosomes. Oncotarget 2016, 7, 74966-74978. [CrossRef]

37. Staubach, S.; Razawi, H.; Hanisch, F.-G. Proteomics of MUC1-containing lipid rafts from plasma membranes and exosomes of human breast carcinoma cells MCF-7. Proteomics 2009, 9, 2820-2835. [CrossRef]

(C) 2020 by the authors. Licensee MDPI, Basel, Switzerland. This article is an open access article distributed under the terms and conditions of the Creative Commons Attribution (CC BY) license (http://creativecommons.org/licenses/by/4.0/). 